\title{
In Arthroscopic Rotator Cuff Surgery, Is There a Difference in the Results of Repair Made With Single or Double Rows According to the Shape and Size of the Tear?
}

Ozgun Karakus ( $\nabla$ ozgunkarakus@hotmail.com )

Omer Halisdemir Universitesi

Ozgur Karaman

Sultan Abdülhamid Han EAH: Sultan Abdulhamid Han Egitim ve Arastirma Hastanesi

Ahmet Sinan Sari

Ömer Halisdemir University: Nigde Omer Halisdemir Universitesi

Baransel Saygi

Maltepe Üniversitesi: Maltepe Universitesi

Research article

Keywords: Rotator Cuff Tears, Shoulder Pain, Rotator Cuff Repair, Arthroscopic Surgery

Posted Date: January 18th, 2021

DOl: https://doi.org/10.21203/rs.3.rs-146662/v1

License: (c) (1) This work is licensed under a Creative Commons Attribution 4.0 International License.

Read Full License 


\section{Abstract}

Introduction

The aim of this study was to evaluate the effect on the results of patients applied with arthroscopic full layer total layer rotator cuff repair made according to the shape and size of the tear.

Materials and Methods

The study included a total of 120 patients applied with arthroscopic full layer rotator cuff repair as single or double row repair, comprising 69 (57.5\%) females and 51 (42.5\%) males. The patients were separated into 3 groups of 40 according to the shape of the tear, as Group A (crescent type), Group B (U type), and Group C ( $L$ type). Within each group, classification was made according to the size of the tear. The longterm postoperative functional results were compared between the groups.

Results

The mean age of the whole sample was $66.68 \pm 6.86$ years (range, $50-81$ years). A statistically significant difference was determined between the groups in respect of Constant Murley (CM), ASES, and UCLA scores $(p<0.05)$. The scores of Group A of all the scales were found to be higher than those of Group $C$ $(p<0.05)$. In single row and double row repair of small and medium-sized tears of all shapes, no significant difference was determined in respect of the CM and UCLA scores ( $p>0.05)$. In the large tears, no significant difference was determined between crescent and U-shaped tears in respect of the CM and UCLA scores $(p>0.05)$.

Conclusions

No significant difference was determined between single and double row repair of crescent type tears of all sizes. In the repair of small and medium-sized $U$ type tears, no significant difference was determined between single and double row repair in respect of the CM and UCLA scores. In large U-shaped tears, the $\mathrm{CM}, \mathrm{ASES}$, and UCLA scores were determined to be high in double row repair. No significant difference was determined between single and double row repair of $L$ type small and medium-sized tears. In the large $L$-shaped tears, the results of the single row repair were found to be higher than those of the cases with double row repair.

\section{Introduction}

Rotator cuff tears are commonly seen in adults aged over 45 years, and they continue to be a common source of pain in the adult population. Rotator cuff tears have been reported to be seen in $25 \%$ of the population aged 60 years and in $50 \%$ of those aged 80 years [1].

In 1944, McLaughlin first described a rotator cuff tear classification according to the geometric shape, which forms the basis of the classification in use today. Surgeons currently separate rotator cuff tears 
into 4 groups as crescent, U-shaped, L-shaped, and massive contracture [2, 3].

A crescent type tear has shorter medial-lateral length than anterior-posterior width. It may be fixed directly to the bone and has medial-lateral movement. Compared to crescent type tears, U-shaped tears extend more medially. The vertex of the tear is more medial and is generally attached to the glenoid edge. These tears are long and narrow and have greater medial -lateral depth than anterior-posterior width. Before tendon bone repair, side-to-side suturing is necessary to reduce tension. L-shaped tears are similar to Ushaped tears, but one side of the tear has more movement than the other. The apex of the $L$ is repaired and the longitudinal split is usually sutured side-to-side. The fourth type of tear defined is a massive, retracted immobile tear, which cannot be repaired because there is no medial-lateral movement. It is estimated that $>90 \%$ of rotator cuff tears fall into the first 3 categories. Of these, the crescent type and Utype are the most common $[4,5]$.

Successful repair of the rotator cuff tendon depends on several factors. Extrinsic factors include successful resoration of the footprint contact area, the quality of the tendon and bone, and for successful healing there must be compression of the tendon to an equal degree with the footprint, and limited movement. The intrinsic factors are weak tendon feeding, hypoxia, tendon atrophy, and fatty filtration of the rotator cuff muscles [6-8].

The single row technique is used as standard in arthroscopic repair of rotator cuff tears. However, in several studies, re-rupture and deficient tendon healing have been reported following this type of repair. There are studies reporting that rotator footprint is not covered at the rate of $52.7 \%$ after single row repair. It is also thought that a natural footprint tendon relationship is not provided after single row repair and this results in incomplete anatomic healing [9-12].

Double row repair has been recommended as a means of increasing the contact area between the natural bone bed and the tendon. Theoretically, it is aimed to increase the tendon-bone coverage area with the help of medial and lateral anchors in this technique $[13,14]$.

By providing a larger coverage area, the double row technique can increase the mechanical strength of the tendon and thereby accelerate tendon healing. Very good results have been reported in arthroscopic repairs made with the double row technique, and some studies have stated that the double row technique is more advantageous anatomically and biomechanically [15-21].

Nevertheless, full consensus has not been reached in literature. There are studies stating that neither technique has superiority over the other. Clinical superiority of the double row technique has not been shown as yet. Previous studies have found no clinically significant difference between the results of repairs made with the single row or double row technique [22-25].

Although comprehensive studies have been made of the results of rotator cuff repair, there are very few studies related to the effect of the tear pattern and size on the functional results. 
The aim of this study was to evaluate the results of repair made according to the shape and size of the tear in patients applied with arthroscopic full layer rotator cuff repair. There are studies in literature related to repair options made according to the size of the tear [26]. However, the clinical effect on the results of single or double row repair made according to both the geometric shape and the size of the tear has not been fully understood. In this study, it was investigated whether or not the repair technique should be selected according to the shape and size of the tear. By comparing all the tear sizes and shapes separately with each other, the results were evaluated in respect of shoulder scores.

\section{Materials And Methods}

The study included a total of 120 patients applied with arthroscopic full layer rotator cuff repair as single or double row repair, comprising 69 (57.5\%) females and 51 (42.5\%) males, with a mean age of $66.68 \pm$ 6.86 years (range, $50-81$ years).

Patients were excluded from the study if they had shoulder instability, degenerative arthritis in the glenohumeral joint, acromioclavicular pathology, tuberculum fracture, previous shoulder surgery because of a fracture, if arthroscopic repair was being applied again because of re-rupture after primary repair, massive contracture immobile tears, arthroscopic subscapularis repair, or cases with grade IV fatty degeneration according to the Goutallier classification.

The patients were separated into 3 groups of 40 according to the shape of the tear. Group A comprised 11 small, 19 medium and 10 large crescent type tears, Group B comprised 10 small, 18 medium and 12 large $U$ type tears, and Group C comprised 10 small, 20 medium and 10 large $L$ type tears. In each group, repair was made with the single row technique to 20 patients and with the double row technique to 20 . In all cases, acromial spurs determined during arthroscopy were lightly corrected with a burr.

On preoperative evaluation with magnetic resonance imaging (MRI) and plain radiographs, the type of full layer rotator cuff tear was determined and the patients were prepared for surgery. Classification of the tear pattern (crescent, $\mathrm{U}$, or L-shape) and size (small: $<1 \mathrm{~cm}$, medium: $1-3 \mathrm{~cm}$, large:3-5cm) was made from the operation report prepared as described previously by the surgeon. All the operation reports were examined by two orthopaedic surgeons. As very few reverse L-shaped and massive tears were determined, they were not included in the study.

The mean follow-up period of the whole study group was 24.2 months (range, 17-32 months). At the final follow-up examination, the patients were evaluated again with the Constant Murley (CM) score, the American Shoulder and Elbow Surgeons score (ASES), the University of California Los Angeles score (UCLA) and the Range of Motion (ROM) values. The ROM values of flexion, abduction, internal and external rotation were measured with a goniometer. The muscle strength test was applied in anterior flexion using a manual muscle test device (Lafayette Muscle Test Device, USA). All the tests were applied by two orthopaedic surgeons at the final follow-up examination. Comparisons were made between the groups in respect of functional shoulder and pain scores. 


\section{Surgical Technique}

All the operations were performed under general anaesthesia with the patient in the beach-chair position. With entry first from the posterior portal, arthroscopic examination was made of the glenohumeral joint. Then, entering the subacromial space, the rotator cuff tear was visualized. Having determined the tear type, side-to-side sutures were used in $\mathrm{U}$ and $\mathrm{L}$-shaped tears. The footprint was determined and the rotator cuff was compressed by applying a $4.5 \mathrm{~mm}$ titanium anchor (Arthrex ${ }^{\circledR}$, Smith \& Nephew ${ }^{\circledR}$ ) with SMC sliding knot, and single row repair was completed. In tears not fully closed, 2 medial anchors were used. In some cases, double row repair was made using a $4.5 \mathrm{~mm}$ pushLock anchor with the tension band method. Subacromial decompression was applied to all cases.

The same postoperative patient follow-up protocol was applied to all the groups. Passive shoulder movements were started on postoperative day one. For 6 weeks, an abduction-support shoulder-arm sling was applied and active shoulder movements were restricted. After 6 weeks, the sling was removed and a physical therapy program including active shoulder movements was applied to all the patients for 2 months. No complications were observed in any patient throughout the postoperative follow-up.

\section{Statistical Analysis}

Data obtained in the study were analysed statistically using NCSS 2007 software (Number Cruncher Statistical System, Kaysville, UT, USA). Using descriptive statistical methods in the evaluation of the data, results were stated as mean \pm standard deviation (SD), median, minimum, maximum values, number $(n)$ and percentage (\%). Conformity of quantitative data to normal distribution was assessed with the Shapiro-Wilk test and graphic evaluations. In the comparisons of $\geq 3$ groups of quantitative data showing normal distribution, the One-way ANOVA test was applied, and in paired comparisons, the Bonferroni test. In the comparison of quantitative data not showing conformity to normal distribution, the Mann Whitney U-test was used for 2 groups, and in the comparisons of $\geq 3$ groups, the Kruskal Wallis test was applied, and in paired comparisons, the Bonferroni-Dunn test. Qualitative data were compared using the Pearson Chi-square test. A value of $p<0.05$ was accepted as statistically significant.

\section{Results}

Evaluation was made of a total of 120 patients as 40 (33.3\%) in Group A with crescent-shaped tear, 40 (33.3\%) in Group B with U-shaped tear, and 40 (33.3\%) in Group C with L-shaped tear. The patients comprised 69 (57.5\%) females and 51 (42.5\%) males, with a mean age of $66.68 \pm 6.86$ years (range, 50-81 years). The operated side was right in $64(53.3 \%)$ cases and left in $56(46.7 \%)$ cases (Table 1$)$.

\section{Evaluations related to the Constant Murley Scores}

\section{Inter-group evaluations:}

Single row repair, a statistically significant difference was determined between the groups in respect of the Constant Murley $(C M)$ scores $(p=0.017 ; p<0.05)$. In the paired comparisons to determine the origin of 
the difference, the Group A scores were found to to be higher than those of Group B $(p=0.046)$ and Group $C(p=0.034)(p<0.05)$.

Double row repair, no statistically significant difference was determined between the groups in respect of the CM scores $(p=0.169 ; p>0.05)$.

All cases; a statistically significant difference was determined between the groups in respect of the $\mathrm{CM}$ scores ( $p=0.016 ; p<0.05)$. In the paired comparisons to determine the origin of the difference, the Group $A$ scores were found to to be higher than those of Group $C(p=0.013, p<0.05)$.

Small tears applied with single-double row repair, no statistically significant difference was determined between the groups in respect of the CM scores $(p=0.973 ; p>0.05$ and $p=0.968 ; p>0,05)$.

All cases with small tears;no statistically significant difference was determined between the groups in respect of the CM scores $(p=0.957 ; p>0.05)$.

Medium tears applied withsingle-double row repair,no statistically significant difference was determined between the groups in respect of the CM scores $(p=0.507 ; p>0.05$ and $p=0.991 ; p>0.05)$.

All cases with medium tears;no statistically significant difference was determined between the groups in respect of the CM scores $(p=0.676 ; p>0.05)$.

Cases with large tears applied with single row repair, the $\mathrm{CM}$ scores of Group A were found to be higher than those of Group B ( $p=0.026)$ and Group C $(p=0.041)(p<0.05)$.

Cases with large tears applied with double row repair, the CM scores of Group A ( $p=0.032)$ and Group B $(p=0.040)$ were found to be higher than those of Group $C(p<0.05)$.

All cases with large tears; a statistically significant difference was determined between the groups in respect of the CM scores $(p=0.001 ; p<0.01)$. In the paired comparisons to determine the origin of the difference, the Group A scores were found to to be higher than those of Group $C(p=0.001, p<0.01)$ (Table 2).

\section{Intra-group Evaluations:}

All cases; no statistically significant difference was determined in the CM scores according to repair type $(p=0.082 ; p>0.05)$.

All cases with small tears; no statistically significant difference was determined in the CM scores according to repair type $(p=0.245 ; p>0.05)$.

All cases with medium tears;no statistically significant difference was determined in the CM scores according to repair type $(p=0.580 ; p>0.05)$. 
All cases with large tears;no statistically significant difference was determined in the CM scores according to repair type $(p=0.560 ; p>0.05)$.

All cases in Group A with small, medium and large tears; no statistically significant difference was determined in the CM scores according to repair type $(p=0.967 ; p>0.05)$.

All cases in Group B; the scores of the group applied with single row repair were determined to be statistically significantly lower than those of the group applied with double row repair $(p=0.022 ; p<0.05)$.

Cases in Group B with small and medium tears; no statistically significant difference was determined in the CM scores according to repair type $(p=0.588 ; p>0.05$, and $p=0.720, p>0.05)$.

Cases in Group B with large tears; the scores of the group applied with single row repair were determined to be statistically significantly lower than those of the group applied with double row repair $(p=0.014$; $\mathrm{p}<0.05)$.

All cases in Group C; no statistically significant difference was determined in the CM scores according to repair type $(p=0.610 ; p>0.05)$.

All cases in Group C with small and medium tears; no statistically significant difference was determined in the CM scores according to repair type $(p=0.445 ; p>0.05$, and $p=0.338, p>0.05)$.

All cases in Group $\mathbf{C}$ with large tears; the scores of the group applied with double row repair were determined to be statistically significantly lower than those of the group applied with single row repair $(p=0.047 ; p<0.05)$.

\section{Intra-Group Evaluations of Small, Medium, and Large Tears}

In the evaluation of small and medium tears, no statistically significant difference was determined between the scores of cases with small tears applied with single row or double row repair and cases with medium tears applied with single row or double row repair $(p>0.05)$.

In the evaluation of small and large tears, the scores of cases with small tears applied with double row repair were statistically significantly higher than those of cases with large tears applied with single row repair $(p=0.006, p<0.01)$. No statistically significant difference was determined in the other comparisons $(p>0.05)$.

In the evaluation of medium and large tears, the scores of cases with medium tears applied with single row repair $(p=0.37)$ and medium tears applied with double row repair $(p=0.003)$ were statistically significantly higher than those of cases with large tears applied with single row repair $(p<0.05)$. No statistically significant difference was determined in the other comparisons $(p>0.05)$.

When the results above are examined, the CM scores showed a difference according to the type of repair, and this difference was seen to originate from the large tear group. The scores of the large tear group 
were found to be lower than those of the small tear group and the medium tear group. As seen in Figure 1, the lowest result was obtained in the Group $\mathrm{C}$ cases with a large tear applied with double row repair (Figure 1).

\section{Evaluations related to the ASES Score Inter-group Evaluations}

All cases applied with single row repair, no statistically significant difference was determined between the groups in respect of the ASES scores $(p=0.088 ; p>0.05)$.

All cases applied with double row repair, no statistically significant difference was determined between the groups in respect of the ASES scores $(p=0.200 ; p>0.05)$.

All cases; a statistically significant difference was determined between the groups in respect of the ASES scores $(p=0.028 ; p<0.05)$. In the paired comparisons to determine from which group the difference originated, the Group A scores were determined to be statistically significantly higher than the scores of Group C $(p=0.023 ; p<0.05)$.

Cases with small tear applied with single row repair, no statistically significant difference was determined between the groups in respect of the ASES scores $(p=0.018 ; p>0.05)$. In the paired comparisons to determine from which group the difference originated, the Group A scores were determined to be statistically significantly higher than the scores of Group B $(p=0.046)$ and Group C $(p=0.046)(p<0.05)$.

Cases with small tear applied with double row repair, no statistically significant difference was determined between the groups in respect of the ASES scores $(p=0.969 ; p>0.05)$.

All cases with small tears; no statistically significant difference was determined between the groups in respect of the ASES scores $(p=0.217 ; p>0.05)$.

Cases with medium tear applied with single-double row repair, no statistically significant difference was determined between the groups in respect of the ASES scores $(p=0.103 ; p>0.05$, and $p=0.999 ; p>0.05)$.

All cases with medium tear,no statistically significant difference was determined between the groups in respect of the ASES scores $(p=0.296 ; p>0.05)$.

Cases with large tear applied with single row repair, a statistically significant difference was determined between the groups in respect of the ASES scores $(p=0.005 ; p<0.01)$. In the paired comparisons to determine from which group the difference originated, the Group A scores were determined to be statistically significantly higher than the scores of Group B $(p=0.012)$ and Group C $(p=0.013)(p<0.05)$.

Cases with large tear applied with double row repair, a statistically significant difference was determined between the groups in respect of the ASES scores $(p=0.008 ; p<0.01)$. In the paired comparisons to 
determine from which group the difference originated, the scores of Group $A(p=0.024)$ and Group B $(p=0.020)$ were determined to be statistically significantly higher than the scores of Group $C(p<0.05)$.

All cases with large tear,a statistically significant difference was determined between the groups in respect of the ASES scores $(p=0.001 ; p<0.01)$. In the paired comparisons to determine from which group the difference originated, the scores of Group A $(p=0.001)$ and Group $B(p=0.024)$ were determined to be statistically significantly higher than the scores of Group $C(p<0.05)$ (Table 3$)$.

\section{Intra-group Evaluations:}

All cases; no statistically significant difference was determined in the ASES scores according to repair type $(p=0.135 ; p>0.05)$.

All cases with small tears; the scores of the single row repair group were determined to be statistically significantly lower than the scores of the double row repair group $(p=0.001 ; p<0.01)$.

All cases with medium tears; no statistically significant difference was determined in the ASES scores according to repair type $(p=0.099 ; p>0.05)$.

All cases with large tears; no statistically significant difference was determined in the ASES scores according to repair type $(p=0.305 ; p>0.05)$.

All cases in Group A with small, medium and large tears; no statistically significant difference was determined in the ASES scores according to repair type $(p=0.712 ; p>0.05)$.

All cases in Group B; no statistically significant difference was determined in the ASES scores according to repair type $(p=0.061 ; p>0.05)$.

All Group B cases with small tear, the scores of the single row repair group were determined to be statistically significantly lower than the scores of the double row repair group $(p=0.009 ; p<0.01)$.

All Group B cases with medium tear, the scores of the single row repair group were determined to be statistically significantly higher than the scores of the double row repair group $(p=0.027 ; p<0.05)$.

All Group B cases with large tear, the scores of the single row repair group were determined to be statistically significantly lower than the scores of the double row repair group $(p=0.004 ; p<0.01)$.

All Group C cases; no statistically significant difference was determined in the ASES scores according to repair type $(p=0.860 ; p>0.05)$.

All Group C cases with small tear, the scores of the single row repair group were determined to be statistically significantly lower than the scores of the double row repair group $(p=0.009 ; p<0.01)$.

All Group C cases with medium tear, no statistically significant difference was determined in the ASES scores according to repair type $(p=0.221 ; p>0.05)$. 
All Group $\mathrm{C}$ cases with large tear, the scores of the single row repair group were determined to be statistically significantly higher than the scores of the double row repair group $(p=0.008 ; p<0.01)(T a b l e$ 3).

\section{Intra-Group Evaluations of Small, Medium, and Large Tears}

In the evaluation of small and medium tears, the scores of cases with small tears applied with double row repair were statistically significantly higher than those of cases with medium tears applied with single row repair $(p=0.001)$ and medium tears applied with double row repair $(p=0.001)(p<0.01)$. No statistically significant difference was determined in the other comparisons $(p>0.05)$.

In the evaluation of small and large tears, the scores of cases with small tears applied with single row repair were statistically significantly higher than those of cases with large tears applied with single row repair $(p=0.001, p<0.01)$. The scores of cases with small tears applied with double row repair were statistically significantly higher than those of cases with large tears applied with single row repair $(p=0.001)$ and large tears applied with double row repair $(p=0.001)(p<0.01)$. No statistically significant difference was determined in the other comparisons $(p>0.05)$.

In the evaluation of medium and large tears, the scores of cases with medium tears applied with single row repair were statistically significantly higher than those of cases with large tears applied with single row repair $(p=0.001)$ and large tears with double row repair $(p=0.018)(p<0.05)$. The scores of cases with medium tears applied with double row repair were statistically significantly higher than those of cases with large tears applied with single row repair $(p<0.001, p<0.01)$. No statistically significant difference was determined in the other comparisons $(p>0.05)$.

When the results above are examined, the ASES scores showed a difference according to the type of repair, and generally this difference was seen to originate from the large tear group. The scores of the large tear group were found to be lower than those of the small tear group and the medium tear group. As seen in Figure 2, the lowest result was obtained in the Group C cases with a large tear applied with double row repair (Figure 2).

\section{Evaluations related to the UCLA Scores}

\section{Inter-group Evaluations}

All cases applied with single row repair, a statistically significant difference was determined between the groups in respect of the UCLA scores $(p=0.024 ; p<0.05)$. In the paired comparisons to determine from which group the difference originated, the scores of Group A were determined to be statistically significantly higher than the scores of Group B $(p=0.031 ; p<0.05)$.

All cases applied with double row repair, no statistically significant difference was determined between the groups in respect of the UCLA scores $(p=0.206 ; p>0.05)$. 
All cases; a statistically significant difference was determined between the groups in respect of the UCLA scores $(p=0.021 ; p<0.05)$. In the paired comparisons to determine from which group the difference originated, the scores of Group A were determined to be statistically significantly higher than the scores of Group C ( $p=0.027 ; p<0.05)$.

All cases with small tear applied with single row repair, no statistically significant difference was determined between the groups in respect of the UCLA scores $(p=0.993 ; p>0.05, p=0.943 ; p>0.05)$.

All cases with small tear, no statistically significant difference was determined between the groups in respect of the UCLA scores $(p=0.977 ; p>0.05)$.

All cases with medium tear applied with single-double row repair, no statistically significant difference was determined between the groups in respect of the UCLA scores $(p=0.588 ; p>0.05, p=0.984, p>0.05)$.

All cases with medium tear, no statistically significant difference was determined between the groups in respect of the UCLA scores $(p=0.713 ; p>0.05)$.

All cases with large tear applied with single row repair, A statistically significant difference was determined between the groups in respect of the UCLA scores $(p=0.003 ; p<0.01)$. In the paired comparisons to determine from which group the difference originated, the scores of Group A were determined to be statistically significantly higher than the scores of Group B $(p=0.015)$ and Group C $(p=0.005) p<0.05)$.

All cases with large tear applied with double row repair, a statistically significant difference was determined between the groups in respect of the UCLA scores $(p=0.008 ; p<0.01)$. In the paired comparisons to determine from which group the difference originated, the scores of Group $A(p=0.022)$ and Group $B(p=0.022)$ were determined to be statistically significantly higher than the scores of Group $C$ $(p<0.05)$.

All cases with large tear,a statistically significant difference was determined between the groups in respect of the UCLA scores $(p=0.001 ; p<0.01)$. In the paired comparisons to determine from which group the difference originated, the scores of Group A $(p=0.001)$ and Group $B(p=0.022)$ were determined to be statistically significantly higher than the scores of Group C $(p<0.05)$ (Table 4).

\section{Intra-Group Evaluations}

All cases; no statistically significant difference was determined in the UCLA scores according to repair type $(p=0.126 ; p>0.05)$.

All cases with small tears; no statistically significant difference was determined in the UCLA scores according to repair type $(p=0.881 ; p>0.05)$.

All cases with medium tears; no statistically significant difference was determined in the UCLA scores according to repair type $(p=0.162 ; p>0.05)$. 
All cases with large tears; no statistically significant difference was determined in the UCLA scores according to repair type $(p=0.592 ; p>0.05)$.

All cases in Group A with small, medium and large tears; no statistically significant difference was determined in the UCLA scores according to repair type $(p=0.890 ; p>0.05)$.

All Group B cases; the scores of the single row repair group were determined to be statistically significantly lower than the scores of the double row repair group $(p=0.010 ; p<0.05)$.

All Group B cases with small and medium tears; no statistically significant difference was determined in the UCLA scores according to repair type $(p=0.905 ; p>0.05$, and $p=0.222, p>0.05)$.

All Group B cases with large tear, the scores of the single row repair group were determined to be statistically significantly lower than the scores of the double row repair group $(p=0.004 ; p<0.01)$.

All Group C cases; no statistically significant difference was determined in the UCLA scores according to repair type $(p=0.946 ; p>0.05)$.

All Group $C$ cases with small and medium tears; no statistically significant difference was determined in the UCLA scores according to repair type $(p=1.000 ; p>0.05$, and $p=0.421, p>0.05)$.

All Group C cases with large tear, the scores of the single row repair group were determined to be statistically significantly higher than the scores of the double row repair group $(p=0.011 ; p<0.05)($ Table 4).

\section{Intra-Group Evaluations of Small, Medium, and Large Tears}

In the evaluation of small and medium tears, no statistically significant difference was determined between the scores of cases with small tears applied with single or double row repair and cases with medium tears applied with single or double row repair $(p>0.05)$.

In the evaluation of small and large tears, the scores of cases with small tears applied with single row repair $(p=0.004)$ and small tears applied with double row repair $(p=0.006)$ were statistically significantly higher than those of cases with large tears applied with single row repair $(p<0.01)$. No statistically significant difference was determined in the other comparisons $(p>0.05)$.

In the evaluation of medium and large tears, the scores of cases with medium tears applied with single row repair were statistically significantly higher than those of cases with large tears applied with single row repair $(p<0.001 ; p<0.01)$

The scores of cases with medium tears applied with double row repair were statistically significantly higher than those of cases with large tears applied with single row repair $(p=0.001)$ and large tears applied with double row repair $(p=0.032)(p<0.05)$. No statistically significant difference was determined in the other comparisons $(p>0.05)$. 
When the results above are examined, the UCLA scores showed a difference according to the type of repair, and this difference was seen to originate from the large tear group. The scores of the large tear group were found to be lower than those of the small tear group and the medium tear group. As seen in Figure 3, the lowest result was obtained in the Group $C$ cases with a large tear applied with double row repair (Figure 3).

\section{Discussion}

To obtain effective repair in rotator cuff tears, biomechanical conditions must be provided. In various biomechanical studies, the double row repair technique has been observed to better reproduce the natural footprint, but the study results remain controversial [27-29]. In studies that have examined tear size irrespective of shape, the double row technique has been recommended for tears $>3 \mathrm{~cm}[30,31]$. Carbonel et al evaluated 160 patients with a 2-year follow-up period, and it was concluded that the UCLA, ASES, and $\mathrm{CM}$ scores of cases with tears $>3 \mathrm{~cm}$ were more successful in double row repair (26). In another study that evaluated single row and double row repair, lower rates of re-rupture were observed in double row repair [32].

There are also studies in literature that have found no significant clinical difference between single row and double row rotator cuff repair. In a meta-analysis by Ying et al, 11 studies were evaluated and no significant clinical difference was found between single and double row repair of tears smaller and larger than $3 \mathrm{~cm}$ [33]. Thus, no consensus has been reached as yet on single row and double row repair techniques. Although there have been studies in recent years recommending double row repair in tears > $3 \mathrm{~cm}$, the treatment type according to both the shape and size of the tear has not been compared in those studies [30, 31].

The most important difference in the current study is that it was aimed to determine the best and worst results by comparing all the sub groups of crescent, $\mathrm{U}$, and $\mathrm{L}$-shape, small, medium and large sizes according to single row and double row repair. In which size and shape of tear the highest and lowest shoulder functional scores were obtained and with what type of repair, were investigated in this study. In a study by Scott Watson et al, in contrast to the hypothesis that there would be better results in crescentshaped tears than in $U$ and $L$-shaped tears, no significant difference was found between the tear shapes after repair. In the first year, single row repair was found to be better than double row repair only in Lshaped tears. In the current study, the results of both single row and double row repair in large crescent type tears were found to be higher compared to $U$ and L-shaped tears. No significant difference was determined for medium and large tears. The reason that the single row repair results of L-shaped large tears were found to be better than those of double row repair in the current study was similar to that of the previously mentioned study [34].

In meta-analyses conducted related to tear size, the shoulder scores have been reported to be higher in double row repair in tears $>3 \mathrm{~cm}$ and the rate of re-rupture has been seen to be lower $[35,36]$. However, the current study was more comprehensive as each tear was compared in respect of both size and shape. 
The study results showed that whatever the size of the tear, when crescent type tears were repaired with single row or double row, no significant difference was determined between the CM, ASES and UCLA scores $(p>0.05)$.

For small and medium-sized U-shaped tears, no significant difference was determined between single and double row repair in respect of CM and UCLA scores. In the large-sized, U-shaped tears, all the scores were higher in double row repair than in single row repair (Tables 2 and 4). In respect of the ASES scores, although double row repair results were higher in small tears, the single row repair scores were found to be higher in medium-sized tears ( $p=0.027, p<0.05$ ). In small and large U-shaped tears, the double row repair ASES scores were higher than those of single row repair, and the single row repair scores were interestingly higher in medium-sized tears, but this was not considered to be clinically significant (Table 3).

In general, in U-shaped tears, double row repair provided higher functional results if the tear was large, whereas no significant difference was found between single and double row repair in small and medium sized tears.

For small and medium L-shaped tears, there was no difference between single and double row repair in respect of CM and UCLA scores. However, the ASES score was seen to be higher in small tears with double row repair compared to single row repair, and in medium-sized tears no difference was determined between single and double row repair. It was interesting that the ASES scores were higher in small $L$ type tears repaired with double row compared to single row repair, but this was not thought to be clinically significant (Table 3). In large $L$ type tears, all the scores were found to be higher with single row repair than double row repair, and the lowest scores were seen in large $L$ type scores repaired with the double row technique compared to all the other groups (Figs. 1-3). It was thought that all the scores were low in the double row repair of $L$ type tears because of excessive tension formed in the tendon.

In a previous study by Park et al, large rotator cuff tears were compared as crescent, $U$ type and $L$ type, and no significant difference was determined in respect of clinical score and re-rupture [37]. Similarly, Wonyong Lee et al compared a group formed of small and medium-sized tears with crescent-shaped tears, and no significant difference was found. However, in that study all the tears were repaired with the single row repair technique [38]. In the current study, a more comprehensive evaluation was made as the scores were examined according to crescent, $U$, and $L$ types.

In the small tears, there was no significant difference in the CM and UCLA scores in respect of the shape of the tear when repaired with single or double row $(p>0.05)$. Whatever the shape, a small tear can be repaired with the single row or double row technique. While there was no significant difference in the ASES score between those repaired with the double row technique, in the single row repair group, the ASES score was higher in the crescent-shaped tears.

In the medium tears, whatever the shape of the tear, there was no difference in all the scores of those with single row repair or double row repair. 
In the large tears, all the scores of the crescent tears with single row repair were higher than those of the $U$ and $L$-shaped tears $(p<0.05)$. So, if single row repair is to be applied to a large tear it should be to the patient group with crescent-shaped tears. In double row repair, there was no difference between the $\mathrm{CM}$ and UCLA scores of the crescent and U-shaped tears and these were higher than those of L-shaped tears. The ASES scores of the crescent -shaped tears in both single and double row repair were higher than those of the $U$ and L-shaped tears.

In this study the ideal protocol was investigated according to the size and shape of each tear, and the functional results were compared of all the groups. Nevertheless, there were some limitations to the study, primarily the low numbers of the subgroups and that the effect on the results was not evaluated of the number of anchors and side-to-side sutures used.

\section{Conclusion}

Whatever the shape of the tear, no difference was determined between single row and double row repair of small and medium tears in respect of the CM and UCLA scores. In crescent-shaped large tears, there was no difference between single and double row repair in all the scores. The CM, ASES and UCLA scores were found to be higher in U-shaped large tears repaired with the double row technique. However, in large L-shaped tears the results of single row repair were found to be higher than for double row repair.

Of all the large tears applied with single row repair, the highest scores were seen in the crescent tears. Of the large tears applied with double row repair, there was no difference in the CM and UCLA scores between the crescent and U-shaped tears, whereas all the scores of the L-shaped large tears were lower than those of the crescent and $U$ type.

\section{Abbreviations}

$\mathrm{CM}$

Constant Murley Score.

ASES

American Shoulder and Elbow Surgeons score.

UCLA

University of California Los Angeles score.

ROM

Range of motion.

MRI

Magnetic resonance imaging.

\section{Declarations}

- Ethical Approval and Consent to participate 
Ethical approval was obtained by T.R. Kayseri Erciyes University Ethics Committee 10/12/2019 No:57

Consent to participate was obtained from the participants.

\section{- Consent for publication}

Written informed consent for publication of their clinical details and/or clinical images was obtained from the patient. A copy of the consent form is available for review by the Editor of this journal.

\section{- Availability of supporting data}

Applicable.

\section{- Competing interests}

The authors declare that they have no conflict of interest.

\section{- Funding}

There is no funding source.

\section{- Authors' contributions}

OK,ASS,BS participated in the design of the study and performed the statistical analysis. OK, ÖK conceived of the study, and participated in its design and coordination and helped to draft the manuscript. OK writing and collecting data.

All authors read and approved the final manuscript.

\section{- Acknowledgements}

Not applicable.

\section{- Authors' information}

1) Ozgun Karakus: Orthopedic Surgeon, Balıkesir City Hospital, Turkey. Mail: ozgunkarakus@hotmail.com

2) Ozgur Karaman: Orthopedic Surgeon, Sultan Abdülhamidhan Teaching and Research Hospital, Istanbul.

Mail: drozgurkaraman@hotmail.com

3) Ahmet Sinan Sari: Assistant Professor of Orthopedic Surgeon, Omer Halisdemir University Hospital, Turkey. Mail: drasinansari@gmail.com

4) Baransel Saygi: Professor of Orthopedic Surgery. Maltepe University, Istanbul. 
Mail: baranselsaygi@yahoo.com

\section{References}

1- Yamamoto A, Takagishi K, Toshihisa Osawa T, et al. Prevalence and risk factors of a rotator cuff tear in the general population. J Shoulder Elbow Surg. 2010 Jan;19(1):116-20.

2-McLaughlin HL. Lesions of the musculotendinous cuff of the shoulder, l: the exposure and treatment of tears with retraction. Clin Orthop Relat Res. 1994 Jul;(304):3-9.

3-Davidson J, Burkhart SS. The geometric classification of rotator cuff tears: a system linking tear pattern to treatment and prognosis. Arthroscopy. 2010 Mar;26(3):417-24.

4-Burkhart SS, Lo IK. Arthroscopic rotator cuff repair. J Am Acad Orthop Surg. 2006 Jun;14(6):333-46.

5- Sallay PI, Hunker PJ, Lim JK. Frequency of various tear patterns in full-thickness tears of the rotator cuff. Arthroscopy. 2007 Oct;23(10):1052-9.

6-Roth K.M, Warth R.J, Lee J.T, et al. Arthroscopic single-row versus double-row repair for full-thickness posterosuperior rotator cuff tears: a critical analysis review. JBJS Rev. 2014 Jul 22;2(7)

7- Park M.C, Cadet E.R, Levine W.N, et al. Tendon-to-Bone pressure distributions at a repaired rotator cuff footprint using transosseous suture and suture anchor fixation techniques. Am J Sports Med. 2005 Aug;33(8):1154-9.

8- Ahmad C.S, Stewart A.M, Izquierdo R, et al. Tendon-bone interface motion in transosseous suture and suture anchor rotator cuff repair techniques. Am J Sports Med. 2005 Nov;33(11):1667-71.

9-Boileau P, Brassart N, Watkinson DJ, et al. Arthroscopic repair of full-thickness tears of the supraspinatus: does the tendon really heal? J Bone Joint Surg Am. 2005 Jun;87(6):1229-40.

10- Charousset C, Duranthon LD, Grimberg J, et al. Arthro-C-scan analysis of rotator cuff tears healing after arthroscopic repair: analysis of predictive factors in a consecutive series of 167 arthroscopic repairs. Rev Chir Orthop Reparatrice Appar Mot. 2006 May;92(3):223-33.

11- Galatz LM, Ball CM, Teefey SA, et al. The outcome and repair integrity of completely arthroscopically repaired large and massive rotator cuff tears. J Bone Joint Surg Am. 2004 Feb;86(2):219-24.

12- Brady PC, Arrigoni P, Burkhart SS. Evaluation of residual rotator cuff defects after in vivo singleversus double-row rotator cuff repairs. Arthroscopy. 2006 Oct;22(10):1070-5.

13-Lo I, Burkhart S. Double-row arthroscopic rotator cuff repair: re-establishing the footprint of the rotator cuff. Arthroscopy. 2003 Nov;19(9):1035-42. 
14-Meier SW, Meier JD. Rotator cuff repair: the effect of double-row fixation on three-dimensional repair site. J Shoulder Elbow Surg. Nov-Dec 2006;15(6):691-6.

15- Apreleva M, Ozbaydar M, Fitzgibbons PG, et al. Rotator cuff tears: the effect of the reconstruction method on three-dimensional repair site area. Arthroscopy. May-Jun 2002;18(5):519-26.

16-Tuoheti Y, Itoi E, Yamamoto N, et al Contact area, contact pressure, and pressure patterns of the tendon-bone interface after rotator cuff repair. Am J Sports Med.2005 Dec;33(12):1869-74.

17-Tauro JC. Arthroscopic rotator cuff repair: analysis of technique and results at 2- and 3-year follow-up. Arthroscopy. Jan-Feb 1998;14(1):45-51.

18-Kim DH, Elattrache NS, Tibone JE. Biomechanical comparison of a single-row versus double-row suture anchor technique for rotator cuff repair. Am J Sports Med. 2006 Mar;34(3):407-14.

19-Snyder SJ. Technique of arthroscopic rotator cuff repair using implantable 4-mm Revo suture anchors, suture Shuttle Relays, and no. 2 nonabsorbable mattress sutures. Orthop Clin North Am. 1997 Apr;28(2):267-75.

20-Smith CD, Alexander S, Hill AM. A biomechanical comparison of single and double-row fixation in arthroscopic rotator cuff repair. J Bone Joint Surg Am. 2006 Nov;88(11):2425-31.

21- Waltrip RL, Zheng N, Dugas JR, et al. Rotator cuff repair. A biomechanical comparison of three techniques. Am J Sports Med. Jul-Aug 2003;31(4):493-7.

22-Franceschi F, Ruzzini L, Longo UG, et al.

Equivalent clinical results of arthroscopic single-row and double-row suture anchor repair for rotator cuff tears: a randomized controlled trial. Am J Sports Med. 2007 Aug;35(8):1254-60.

23-Grasso A, Milano G, Salvatore M, et al. Single-row versus double-row arthroscopic rotator cuff repair: a prospective randomized clinical study. Arthroscopy. 2009 Jan;25(1):4-12.

24- Koh KH, Kang KC, Lim TK, et al. Prospective randomized clinical trial of single- versus double-row suture anchor repair in 2- to 4-cm rotator cuff tears: clinical and magnetic resonance imaging results. Arthroscopy. 2011 Apr;27(4):453-62.

25- Lapner PL, Sabri E, Rakhra K, et al. A multicenter randomized controlled trial comparing single-row with double-row fixation in arthroscopic rotator cuff repair.J Bone Joint Surg Am. 2012 Jul 18;94(14):1249-57.

26-Carbonel I, Martinez AA, Calvo A, et al. Single-row versus double-row arthroscopic repair in the treatment of rotator cuff tears: a prospective randomized clinical study. Int Orthop. 2012 Sep;36(9):187783. 
27-Ahmad C.S, Kleweno C, Jacir A.M, et al. Biomechanical performance of rotator cuff repairs with humeral rotation: a new rotator cuff repair failure model. Am J Sports Med. 2008 May;36(5):888-92.

28- Esquivel A.O., Duncan D.D., Dobrasevic N., et al. Load to failure and stiffness: anchor placement and suture pattern effects on load to failure in rotator cuff repairs. Orthop J Sports Med. 2015 Apr 7;3(4):23.

29-. Ma C.B., Comerford L., Wilson J., et al. Biomechanical evaluation of arthroscopic rotator cuff repairs: double-row compared with single-row fixation. J Bone Joint Surg Am. 2006 Feb;88(2):403-10.

30-Zhang Q, Ge H, Zhou J, et al. Single-row or double-row fixation technique for full-thickness rotator cuff tears: a meta-analysis. PLoS One. 2013 Jul 11;8(7):e68515.

31-Xu C, Zhao J, Li D. Meta-analysis comparing single-row and doublerow repair techniques in the arthroscopic treatment of rotator cuff tears. J Shoulder Elbow Surg. 2014Feb;23(2):182-8.

32- Millett PJ, Warth RJ, Dornan GJ, et al. Clinical and structural outcomes after arthroscopic single-row versus doublerow rotator cuff repair: a systematic review and meta-analysis of level I randomized clinical trials. J Shoulder Elbow Surg. 2014 Apr;23(4):586-97.

33-Ying Z, Lin T, Yan S. Arthroscopic Single-row versus Double-row Technique for Repairing Rotator Cuff Tears: a Systematic Review and Meta-analysis.

Orthop Surg. 2014 Nov; 6(4): 300-312.

34- Watson S, Allen B, Robbins C, et al. Does the Rotator Cuff Tear Pattern Influence Clinical Outcomes After Surgical Repair? Orthop J Sports Med. 2018 Mar; 6(3): 2325967118763107.

35-Saridakis P, Jones G. Outcomes of single-row and double-row arthroscopic rotator cuff repair: a systematic review. J Bone Joint Surg Am. 2010 Mar;92(3):732-42.

36-Chen M, Xu W, Dong Q, et al. Outcomes of single-row versus double-row arthroscopic rotator cuff repair: a systematic review and meta-analysis of current evidence. Arthroscopy. 2013 Aug;29(8):1437-49.

37-Park JY, Jung SW, Jeon SH, et al. Arthroscopic repair of large U-shaped rotator cuff tears without margin convergence versus repair of crescent- or L-shaped tears. Am J Sports Med. 2014 Jan;42(1):10311.

38-Wonyong L, Sung-Jae K, Chong-Hyuk C, et al. Clinical outcomes and structural integrity of C-shaped rotator cuff tears after arthroscopic repair: comparison with crescent-shaped tears. J Orthop Surg Res. 2018 Jun; 13:154.

\section{Tables}

Table 1: Evaluation of the Descriptive Characteristics of the Groups. 


\begin{tabular}{|c|c|c|c|c|c|c|}
\hline & & $\begin{array}{l}\text { Total } \\
(n=120)\end{array}$ & $\begin{array}{l}\text { Group A } \\
(n=40)\end{array}$ & $\begin{array}{l}\text { Group B } \\
(n=40)\end{array}$ & $\begin{array}{l}\text { Group C } \\
(n=40)\end{array}$ & $p$ \\
\hline \multirow[t]{2}{*}{$\begin{array}{l}\text { Age } \\
\text { (years) }\end{array}$} & $\begin{array}{l}\text { Min-Max } \\
\text { (Median) }\end{array}$ & $50-81(66)$ & $50-81(63)$ & $50-81(67)$ & $57-81(70)$ & \multirow[t]{2}{*}{${ }^{a} 0.001 * *$} \\
\hline & $M e a n \pm S D$ & $66.68 \pm 6.86$ & $64.23 \pm 5.84$ & $66.05 \pm 6.06$ & $69.75 \pm 7.52$ & \\
\hline \multirow[t]{2}{*}{ Gender } & Female & $69(57.5)$ & $24(60)$ & $27(67.5)$ & $18(45)$ & \multirow[t]{2}{*}{${ }^{d} 0.135$} \\
\hline & Male & $51(42.5)$ & $16(40)$ & 13 (32.5) & $22(55)$ & \\
\hline \multirow[t]{2}{*}{ Side } & Right & 64 (53.3) & $25(62.5)$ & $16(40)$ & $23(57.5)$ & \multirow[t]{2}{*}{${ }^{d} 0.118$} \\
\hline & Left & $56(46.7)$ & 15 (37.5) & $24(60)$ & $17(42.5)$ & \\
\hline \multirow{2}{*}{$\begin{array}{l}\text { Repair } \\
\text { type }\end{array}$} & Single row & $60(50)$ & $20(50)$ & $20(50)$ & $20(50)$ & \multirow[t]{2}{*}{${ }^{d} 1.000$} \\
\hline & Double row & $60(50)$ & $20(50)$ & $20(50)$ & $20(50)$ & \\
\hline \multirow{3}{*}{$\begin{array}{l}\text { Size of } \\
\text { tear }\end{array}$} & Small & $31(25.8)$ & $11(27.5)$ & $10(25)$ & $10(25)$ & \multirow[t]{3}{*}{${ }^{d} 0.989$} \\
\hline & Medium & $57(47.5)$ & $19(47.5)$ & $18(45)$ & $20(50)$ & \\
\hline & Large & $32(26.7)$ & $10(25)$ & $12(30)$ & $10(25)$ & \\
\hline
\end{tabular}

a One-way ANOVA Test

${ }^{d}$ Pearson Chi-Square Test

${ }^{*} p<0.05$

${ }^{* *} p<0.01$

Table 2: Evaluations related to the Constant Murley Score. 


\begin{tabular}{|c|c|c|c|c|c|c|c|}
\hline \multicolumn{2}{|c|}{$\begin{array}{l}\text { Constant Murley } \\
\text { score }\end{array}$} & \multirow{2}{*}{$\begin{array}{l}\text { All cases } \\
\text { Mean } \pm S D \\
\text { (Median) }\end{array}$} & \multirow{2}{*}{$\begin{array}{l}\text { Group A } \\
\text { Mean } \pm S D \\
\text { (Median) }\end{array}$} & \multirow{2}{*}{$\begin{array}{l}\text { Group B } \\
\text { Mean } \pm S D \\
\text { (Median) }\end{array}$} & \multirow{2}{*}{$\begin{array}{l}\text { Group C } \\
\text { Mean } \pm S D \\
\text { (Median) }\end{array}$} & \multirow[t]{2}{*}{$p$} & \multirow[t]{2}{*}{$\begin{array}{l}\text { Post } \\
\text { hoc }\end{array}$} \\
\hline & & & & & & & \\
\hline \multirow[t]{4}{*}{$\begin{array}{l}\text { All } \\
\text { cases }\end{array}$} & $\begin{array}{l}\text { Single } \\
\text { row }\end{array}$ & $\begin{array}{l}81.82 \pm 2.80 \\
(80)\end{array}$ & $\begin{array}{l}83.25 \pm 3.27 \\
(83)\end{array}$ & $\begin{array}{l}81.15 \pm 2.37 \\
(80)\end{array}$ & $\begin{array}{l}81.05 \pm 2.19 \\
(80)\end{array}$ & ${ }^{a} 0.017^{*}$ & $\begin{array}{l}A>B, \\
C\end{array}$ \\
\hline & $\begin{array}{l}\text { Double } \\
\text { row }\end{array}$ & $\begin{array}{l}82.63 \pm 3.43 \\
(83)\end{array}$ & $\begin{array}{l}83.25 \pm 3.16 \\
(83)\end{array}$ & $\begin{array}{l}83.20 \pm 3.07 \\
(83)\end{array}$ & $\begin{array}{l}81.45 \pm 3.87 \\
(82)\end{array}$ & ${ }^{a} 0.169$ & - \\
\hline & ${ }^{c} p$ & 0.082 & 0.967 & $0.022 *$ & 0.610 & & \\
\hline & Total & $\begin{array}{l}82.23 \pm 3.15 \\
(82)\end{array}$ & $\begin{array}{l}83.25 \pm 3.18 \\
(83)\end{array}$ & $\begin{array}{l}82.18 \pm 2.90 \\
(82)\end{array}$ & $\begin{array}{l}81.25 \pm 3.11 \\
(80)\end{array}$ & ${ }^{a} 0.016 *$ & $A>C$ \\
\hline \multirow[t]{4}{*}{$\begin{array}{l}\text { Small } \\
\text { tear }\end{array}$} & $\begin{array}{l}{ }^{1} \text { Single } \\
\text { row } \\
(n=16)\end{array}$ & $\begin{array}{l}82.00 \pm 2.61 \\
(82)\end{array}$ & $\begin{array}{l}82.50 \pm 3.94 \\
(82)\end{array}$ & $\begin{array}{l}81.80 \pm 1.79 \\
(82)\end{array}$ & $\begin{array}{l}81.60 \pm 1.52 \\
(82)\end{array}$ & ${ }^{b} 0.973$ & - \\
\hline & $\begin{array}{l}{ }^{2} \text { Double } \\
\text { row } \\
(n=15)\end{array}$ & $\begin{array}{l}83.27 \pm 3.43 \\
(83)\end{array}$ & $\begin{array}{l}83.40 \pm 3.71 \\
(84)\end{array}$ & $\begin{array}{l}83.20 \pm 3.70 \\
(83)\end{array}$ & $\begin{array}{l}83.20 \pm 3.70 \\
(83)\end{array}$ & ${ }^{b} 0.968$ & - \\
\hline & ${ }^{c} p$ & 0.245 & 0.507 & 0.588 & 0.445 & & \\
\hline & $\begin{array}{l}\text { Small } \\
\text { tear total }\end{array}$ & $\begin{array}{l}82.61 \pm 3.05 \\
(83)\end{array}$ & $\begin{array}{l}82.91 \pm 3.67 \\
(84)\end{array}$ & $\begin{array}{l}82.50 \pm 2.84 \\
(83)\end{array}$ & $\begin{array}{l}82.40 \pm 2.80 \\
(83)\end{array}$ & ${ }^{b} 0.957$ & - \\
\hline \multirow[t]{4}{*}{$\begin{array}{l}\text { Medium } \\
\text { tear }\end{array}$} & $\begin{array}{l}{ }^{3} \text { Single } \\
\text { row } \\
(n=27)\end{array}$ & $\begin{array}{l}82.30 \pm 2.73 \\
(83)\end{array}$ & $\begin{array}{l}83.22 \pm 2.73 \\
(83)\end{array}$ & $\begin{array}{l}82.13 \pm 2.90 \\
(82)\end{array}$ & $\begin{array}{l}81.60 \pm 2.63 \\
(80)\end{array}$ & ${ }^{b} 0.507$ & - \\
\hline & $\begin{array}{l}{ }^{4} \text { Double } \\
\text { row } \\
(n=30)\end{array}$ & $\begin{array}{l}82.87 \pm 2.73 \\
(83)\end{array}$ & $\begin{array}{l}82.80 \pm 2.90 \\
(83)\end{array}$ & $\begin{array}{l}82.90 \pm 2.81 \\
(83)\end{array}$ & $\begin{array}{l}82.90 \pm 2.77 \\
(82)\end{array}$ & ${ }^{b} 0.991$ & - \\
\hline & ${ }^{c} p$ & 0.580 & 0.701 & 0.720 & 0.338 & & \\
\hline & $\begin{array}{l}\text { Medium } \\
\text { tear total }\end{array}$ & $\begin{array}{l}82.60 \pm 2.72 \\
(83)\end{array}$ & $\begin{array}{l}83.00 \pm 2.75 \\
(83)\end{array}$ & $\begin{array}{l}82.56 \pm 2.79 \\
(83)\end{array}$ & $\begin{array}{l}82.25 \pm 2.71 \\
(82)\end{array}$ & ${ }^{b} 0.676$ & - \\
\hline \multirow[t]{4}{*}{$\begin{array}{l}\text { Large } \\
\text { tear }\end{array}$} & $\begin{array}{l}{ }^{5} \text { Single } \\
\text { row } \\
(n=17)\end{array}$ & $\begin{array}{l}80.88 \pm 3.02 \\
(80)\end{array}$ & $\begin{array}{l}84.20 \pm 3.83 \\
(87)\end{array}$ & $\begin{array}{l}79.57 \pm 1.13 \\
(79)\end{array}$ & $\begin{array}{l}79.40 \pm 0.55 \\
(79)\end{array}$ & ${ }^{b} 0.018^{*}$ & $\begin{array}{l}A>B, \\
C\end{array}$ \\
\hline & $\begin{array}{l}{ }^{6} \text { Double } \\
\text { row } \\
(n=15)\end{array}$ & $\begin{array}{l}81.53 \pm 4.55 \\
(80)\end{array}$ & $\begin{array}{l}84.00 \pm 3.67 \\
(86)\end{array}$ & $\begin{array}{l}83.80 \pm 3.56 \\
(85)\end{array}$ & $\begin{array}{l}75.80 \pm 2.05 \\
(76)\end{array}$ & ${ }^{b} 0.015^{*}$ & $\begin{array}{l}A \\
B>C\end{array}$ \\
\hline & ${ }^{c} p$ & 0.560 & 0.729 & $0.014^{*}$ & $0.047^{*}$ & & \\
\hline & $\begin{array}{l}\text { Large } \\
\text { tear total }\end{array}$ & $\begin{array}{l}81.19 \pm 3.76 \\
(80)\end{array}$ & $\begin{array}{l}84.10 \pm 3.54 \\
(87)\end{array}$ & $\begin{array}{l}81.33 \pm 3.17 \\
(80)\end{array}$ & $\begin{array}{l}78.10 \pm 1.97 \\
(79)\end{array}$ & ${ }^{b} 0.001$ ** & $A>C$ \\
\hline
\end{tabular}




\begin{tabular}{|lllll|}
\hline Small - Medium tear & & & & \\
\hline${ }^{c} p(1-3)$ & 0,701 & 0.720 & 0.881 & 0.799 \\
\hline${ }^{c} p(1-4)$ & 0,430 & 0.912 & 0.573 & 0.487 \\
\hline${ }^{c} p(2-3)$ & 0,340 & 0.733 & 0.654 & 0.375 \\
\hline${ }^{c} p(2-4)$ & 0,492 & 0.533 & 0.802 & 0.756 \\
\hline Small - Large tear & & & & \\
\hline${ }^{c} p(1-5)$ & 0,058 & 0.350 & $0.017^{*}$ & $0.021^{*}$ \\
\hline${ }^{c} p(1-6)$ & 0,762 & 0.354 & 0.331 & $0.014^{*}$ \\
\hline${ }^{c} p(2-5)$ & $0,006^{* *}$ & 0.742 & $0.014^{*}$ & $0.022^{*}$ \\
\hline${ }^{c} p(2-6)$ & 0,277 & 0.745 & 0.746 & $0.014^{*}$ \\
\hline Medium - Large tear & & & & \\
\hline${ }^{c} p(3-5)$ & $0,037^{*}$ & 0.783 & $0.049^{*}$ & 0.071 \\
\hline${ }^{c} p(3-6)$ & 0,698 & 0.837 & 0.204 & $0.009^{* *}$ \\
\hline${ }^{c} p(4-5)$ & $0,003^{* *}$ & 0.571 & $0.006^{* *}$ & $0.010^{*}$ \\
\hline${ }^{c} p(4-6)$ & 0,222 & 0.617 & 0.709 & $0.004^{* *}$ \\
\hline & & & & \\
\hline
\end{tabular}

${ }^{a}$ One-way ANOVA Test $\quad{ }^{b}$ Kruskal Wallis Test $\quad{ }^{c}$ Mann Whitney U Test $\quad{ }^{*} p<0.05$
${ }^{* *} p<0.01$

Table 3: Evaluations Related to the ASES Score. 


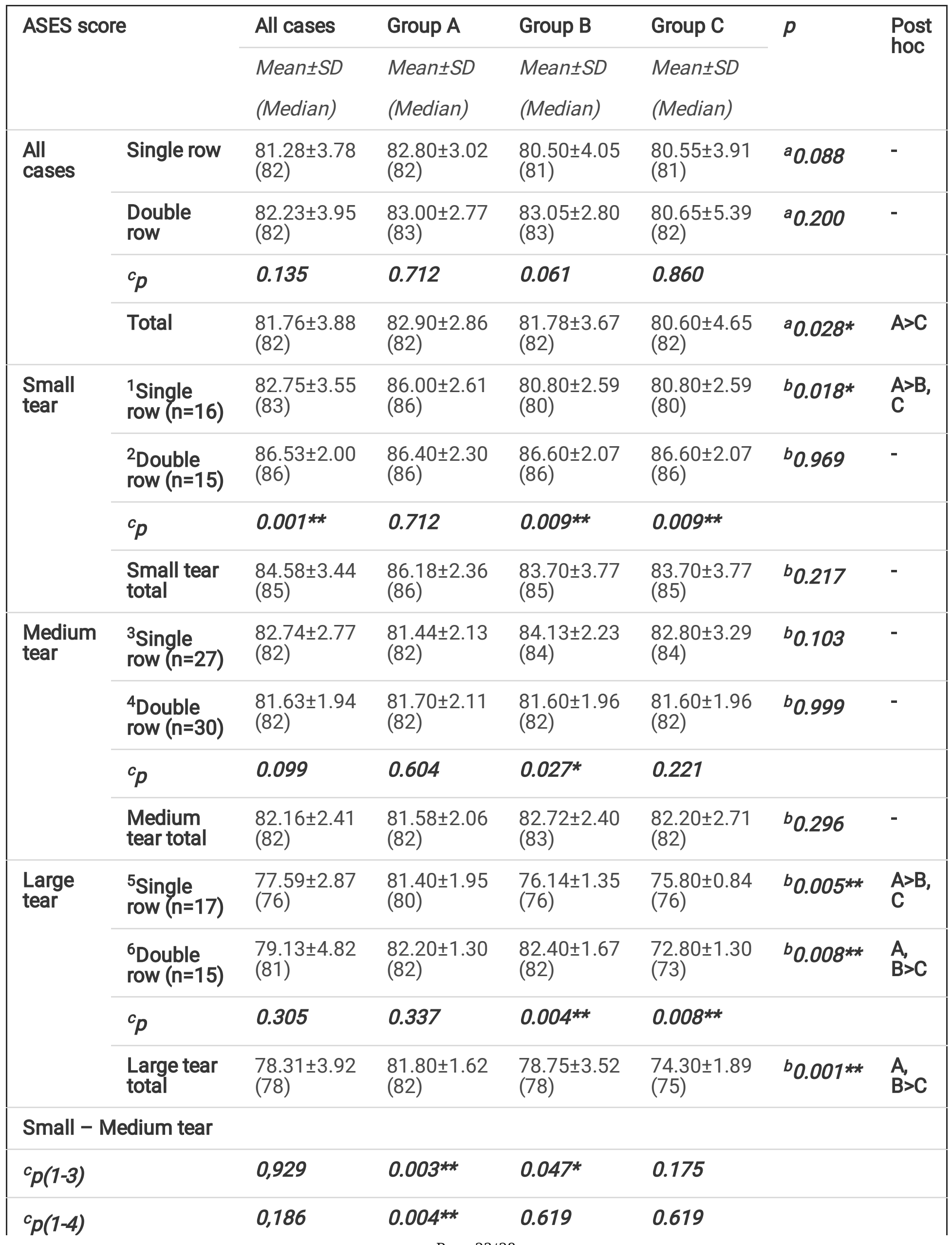




\begin{tabular}{|lllll|}
\hline${ }^{c} p(2-3)$ & $0,001^{* *}$ & $0.004^{* *}$ & 0.065 & $0.019^{*}$ \\
\hline${ }^{c} p(2-4)$ & $0,001^{* *}$ & $0.004^{* *}$ & $0.002^{* *}$ & $0.002^{* *}$ \\
\hline Small - Large tear & & & & \\
\hline${ }^{c} p(1-5)$ & $0,001^{* *}$ & $0.016^{*}$ & $0.008^{* *}$ & $0.009^{* *}$ \\
\hline${ }^{c} p(1-6)$ & 0,068 & $0.017^{*}$ & 0.293 & $0.009^{* *}$ \\
\hline${ }^{c} p(2-5)$ & $0,001^{* *}$ & $0.011^{*}$ & $0.004^{* *}$ & $0.008^{* *}$ \\
\hline${ }^{c} p(2-6)$ & $0,001^{* *}$ & $0.012^{*}$ & $0.015^{*}$ & $0.009^{* *}$ \\
\hline Medium - Large tear & & & & \\
\hline${ }^{c} p(3-5)$ & $0,001^{* *}$ & 0.783 & $0.001^{*}$ & $0.005^{* *}$ \\
\hline${ }^{c} p(3-6)$ & $0,018^{*}$ & 0.577 & 0.160 & $0.002^{* *}$ \\
\hline${ }^{c} p(4-5)$ & $0,001^{* *}$ & 0.661 & $0.001^{* *}$ & $0.002^{* *}$ \\
\hline${ }^{c} p(4-6)$ & 0,144 & 0.802 & 0.706 & $0.002^{* *}$ \\
\hline
\end{tabular}

a One-way ANOVA Test $\quad{ }^{b}$ Kruskal Wallis Test $\quad{ }^{c}$ Mann Whitney U Test $\quad{ }^{*} p<0.05$ ${ }^{* *} p<0.01$

Table 4: Evaluations Related to the UCLA Score. 


\begin{tabular}{|c|c|c|c|c|c|c|c|}
\hline \multicolumn{2}{|c|}{ UCLA score } & \multirow{2}{*}{$\begin{array}{l}\text { All cases } \\
\text { Mean } \pm S D \\
\text { (Median) }\end{array}$} & \multirow{2}{*}{$\begin{array}{l}\text { Group A } \\
\text { Mean } \pm S D \\
\text { (Median) }\end{array}$} & \multirow{2}{*}{$\begin{array}{l}\text { Group B } \\
\text { Mean } \pm S D \\
(\text { Median)) }\end{array}$} & \multirow{2}{*}{$\begin{array}{l}\text { Group C } \\
\text { Mean } \pm S D \\
\text { (Median) }\end{array}$} & \multirow[t]{2}{*}{$p$} & \multirow{2}{*}{$\begin{array}{l}\text { Post } \\
\text { hoc }\end{array}$} \\
\hline & & & & & & & \\
\hline \multirow[t]{4}{*}{$\begin{array}{l}\text { All } \\
\text { cases }\end{array}$} & Single row & $\begin{array}{l}28.33 \pm 2.31 \\
(29)\end{array}$ & $\begin{array}{l}29.45 \pm 1.93 \\
(29)\end{array}$ & $\begin{array}{l}27.60 \pm 2.30 \\
(27)\end{array}$ & $\begin{array}{l}27.95 \pm 2.35 \\
(28)\end{array}$ & ${ }^{a} 0.024^{*}$ & $A>B$ \\
\hline & $\begin{array}{l}\text { Double } \\
\text { row }\end{array}$ & $\begin{array}{l}28.87 \pm 2.72 \\
(29)\end{array}$ & $\begin{array}{l}29.40 \pm 1.96 \\
(29)\end{array}$ & $\begin{array}{l}29.40 \pm 2.04 \\
(29)\end{array}$ & $\begin{array}{l}27.80 \pm 3.64 \\
(28)\end{array}$ & ${ }^{a} 0.206$ & - \\
\hline & ${ }^{c} p$ & 0.126 & 0.890 & $0.010^{*}$ & 0.946 & & \\
\hline & Total & $\begin{array}{l}28.60 \pm 2.53 \\
(29)\end{array}$ & $\begin{array}{l}29.43 \pm 1.92 \\
(29)\end{array}$ & $\begin{array}{l}28.50 \pm 2.33 \\
(29)\end{array}$ & $\begin{array}{l}27.88 \pm 3.02 \\
(28)\end{array}$ & ${ }^{a} 0.021 *$ & $A>C$ \\
\hline \multirow[t]{4}{*}{$\begin{array}{l}\text { Small } \\
\text { tear }\end{array}$} & $\begin{array}{l}{ }^{1} \text { Single } \\
\text { row }(n=16)\end{array}$ & $\begin{array}{l}28.94 \pm 2.02 \\
(29)\end{array}$ & $\begin{array}{l}29.50 \pm 3.21 \\
(28)\end{array}$ & $\begin{array}{l}28.60 \pm 0.89 \\
(29)\end{array}$ & $\begin{array}{l}28.60 \pm 0.89 \\
(29)\end{array}$ & ${ }^{b} 0.993$ & - \\
\hline & $\begin{array}{l}{ }^{2} \text { Double } \\
\text { row }(n=15)\end{array}$ & $\begin{array}{l}28.60 \pm 1.40 \\
(29)\end{array}$ & $\begin{array}{l}28.40 \pm 1.34 \\
(29)\end{array}$ & $\begin{array}{l}28.60 \pm 1.67 \\
(29)\end{array}$ & $\begin{array}{l}28.80 \pm 1.48 \\
(29)\end{array}$ & ${ }^{b} 0.943$ & - \\
\hline & ${ }^{c} p$ & 0.881 & 0.847 & 0.905 & 1.000 & & \\
\hline & $\begin{array}{l}\text { Small tear } \\
\text { total }\end{array}$ & $\begin{array}{l}28.77 \pm 1.73 \\
(29)\end{array}$ & $\begin{array}{l}29.00 \pm 2.49 \\
(29)\end{array}$ & $\begin{array}{l}28.60 \pm 1.26 \\
(29)\end{array}$ & $\begin{array}{l}28.70 \pm 1.16 \\
(29)\end{array}$ & ${ }^{b} 0.977$ & - \\
\hline \multirow[t]{4}{*}{$\begin{array}{l}\text { Medium } \\
\text { tear }\end{array}$} & $\begin{array}{l}{ }^{3} \text { Single } \\
\text { row }(n=27)\end{array}$ & $\begin{array}{l}29.11 \pm 1.97 \\
(29)\end{array}$ & $\begin{array}{l}29.33 \pm 1.41 \\
(29)\end{array}$ & $\begin{array}{l}28.88 \pm 2.47 \\
(28)\end{array}$ & $\begin{array}{l}29.10 \pm 2.13 \\
(29)\end{array}$ & ${ }^{b} 0.588$ & - \\
\hline & $\begin{array}{l}{ }^{4} \text { Double } \\
\text { row }(n=30)\end{array}$ & $\begin{array}{l}29.93 \pm 2.30 \\
(29)\end{array}$ & $\begin{array}{l}30.00 \pm 2.31 \\
(29)\end{array}$ & $\begin{array}{l}29.90 \pm 2.42 \\
(29)\end{array}$ & $\begin{array}{l}29.90 \pm 2.42 \\
(29)\end{array}$ & ${ }^{b} 0.984$ & - \\
\hline & $c_{p}$ & 0.162 & 0.735 & 0.222 & 0.421 & & \\
\hline & $\begin{array}{l}\text { Medium } \\
\text { tear total }\end{array}$ & $\begin{array}{l}29.54 \pm 2.17 \\
(29)\end{array}$ & $\begin{array}{l}29.68 \pm 1.92 \\
(29)\end{array}$ & $\begin{array}{l}29.44 \pm 2.43 \\
(29)\end{array}$ & $\begin{array}{l}29.50 \pm 2.26 \\
(29)\end{array}$ & ${ }^{b} 0.713$ & - \\
\hline \multirow[t]{4}{*}{$\begin{array}{l}\text { Large } \\
\text { tear }\end{array}$} & $\begin{array}{l}{ }^{5} \text { Single } \\
\text { row }(n=17)\end{array}$ & $\begin{array}{l}26.53 \pm 2.18 \\
(25)\end{array}$ & $\begin{array}{l}29.60 \pm 0.89 \\
(29)\end{array}$ & $\begin{array}{l}25.43 \pm 0.79 \\
(25)\end{array}$ & $\begin{array}{l}25.00 \pm 0.71 \\
(25)\end{array}$ & ${ }^{b} 0.003^{* *}$ & $\begin{array}{l}A>B, \\
C\end{array}$ \\
\hline & $\begin{array}{l}{ }^{6} \text { Double } \\
\text { row }(n=15)\end{array}$ & $\begin{array}{l}27.00 \pm 3.46 \\
(29)\end{array}$ & $\begin{array}{l}29.20 \pm 1.48 \\
(29)\end{array}$ & $\begin{array}{l}29.20 \pm 1.48 \\
(29)\end{array}$ & $\begin{array}{l}22.60 \pm 1.14 \\
(23)\end{array}$ & ${ }^{b} 0.008^{* *}$ & $\begin{array}{l}A \\
B>C\end{array}$ \\
\hline & ${ }^{c} p$ & 0.592 & 0.736 & $0.004^{* *}$ & $0.011^{*}$ & & \\
\hline & $\begin{array}{l}\text { Large tear } \\
\text { total }\end{array}$ & $\begin{array}{l}26.75 \pm 2.82 \\
(27)\end{array}$ & $\begin{array}{l}29.40 \pm 1.17 \\
(29)\end{array}$ & $\begin{array}{l}27.00 \pm 2.22 \\
(27)\end{array}$ & $\begin{array}{l}23.80 \pm 1.55 \\
(24)\end{array}$ & ${ }^{b} 0.001 * *$ & $\begin{array}{l}A, \\
B>C\end{array}$ \\
\hline \multicolumn{8}{|c|}{ Small - Medium tear } \\
\hline${ }^{c} p(1-3)$ & & 0.786 & 0.590 & 0.760 & 0.850 & & \\
\hline${ }^{c} p(1-4)$ & & 0.276 & 0.441 & 0.567 & 0.567 & & \\
\hline
\end{tabular}




\begin{tabular}{|lllll|}
\hline${ }^{c} p(2-3)$ & 0.537 & 0.336 & 1.000 & 0.950 \\
\hline${ }^{c} p(2-4)$ & 0.105 & 0.261 & 0.350 & 0.492 \\
\hline Small - Large tear & & & & \\
\hline${ }^{c} p(1-5)$ & $0.004^{* *}$ & 0.509 & $0.003^{* *}$ & $0.006^{* *}$ \\
\hline${ }^{c} p(1-6)$ & 0.385 & 0.777 & 0.345 & $0.007^{* *}$ \\
\hline${ }^{c} p(2-5)$ & $0.006^{* *}$ & 0.178 & $0.005^{* *}$ & $0.008^{* *}$ \\
\hline${ }^{c} p(2-6)$ & 0.431 & 0.381 & 0.511 & $0.009^{* *}$ \\
\hline Medium - Large tear & & & & \\
\hline${ }^{c} p(3-5)$ & $0.001^{* *}$ & 0.485 & $0.002^{* *}$ & $0.002^{* *}$ \\
\hline${ }^{c} p(3-6)$ & 0.148 & 0.945 & 0.597 & $0.002^{* *}$ \\
\hline${ }^{c} p(4-5)$ & $0.001^{* *}$ & 0.753 & $0.001^{* *}$ & $0.002^{* *}$ \\
\hline${ }^{c} p(4-6)$ & $0.032^{*}$ & 0.755 & 0.804 & $0.002^{* *}$ \\
\hline
\end{tabular}

a One-way ANOVA Test $\quad{ }^{b}$ Kruskal Wallis Test $\quad{ }^{c}$ Mann Whitney U Test $\quad{ }^{*} p<0.05$ ${ }^{* *} p<0.01$

Figures 


\section{Consant Murley Score}

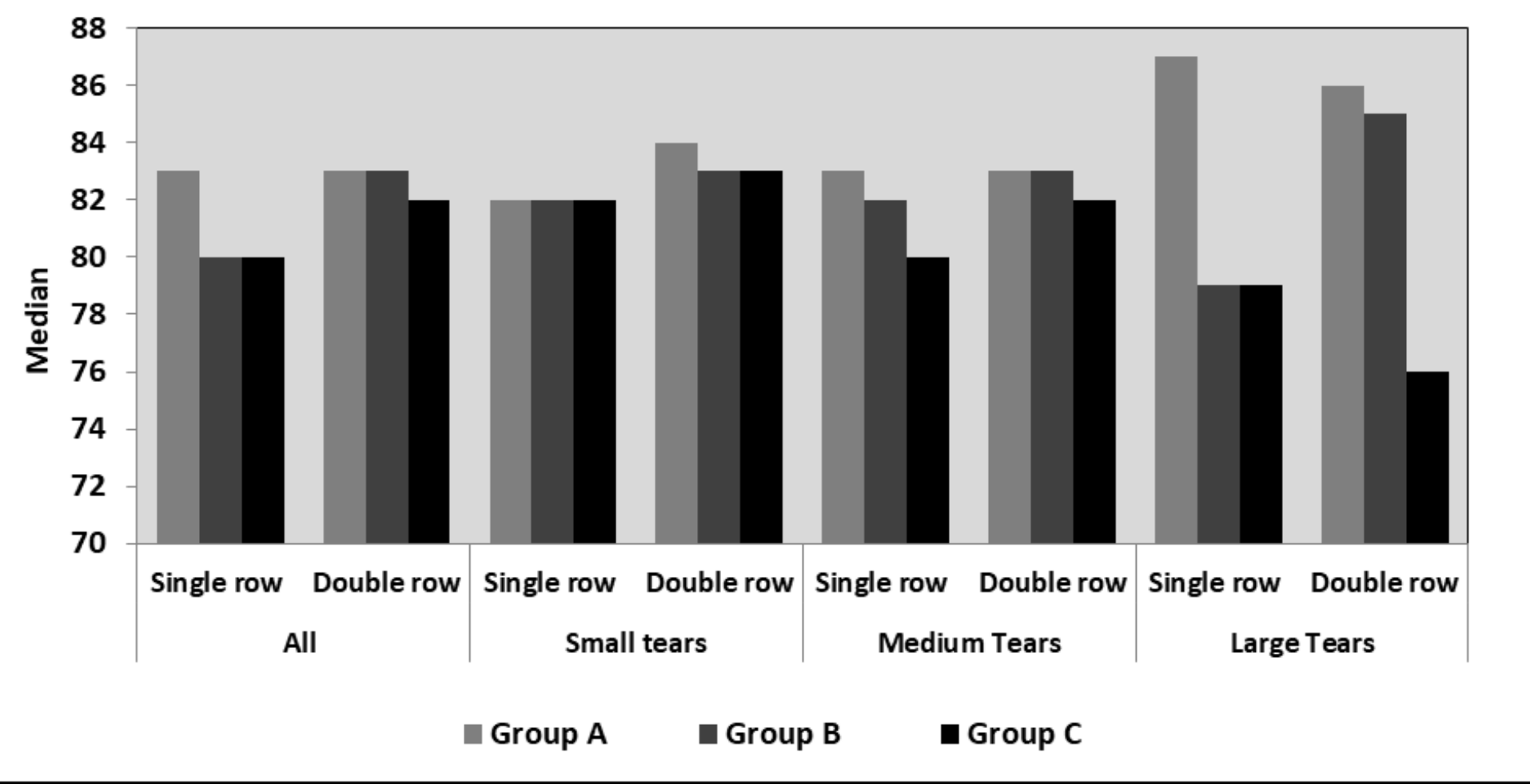

Figure 1

Distribution of the Constant Murley scores.

\section{ASES Score}

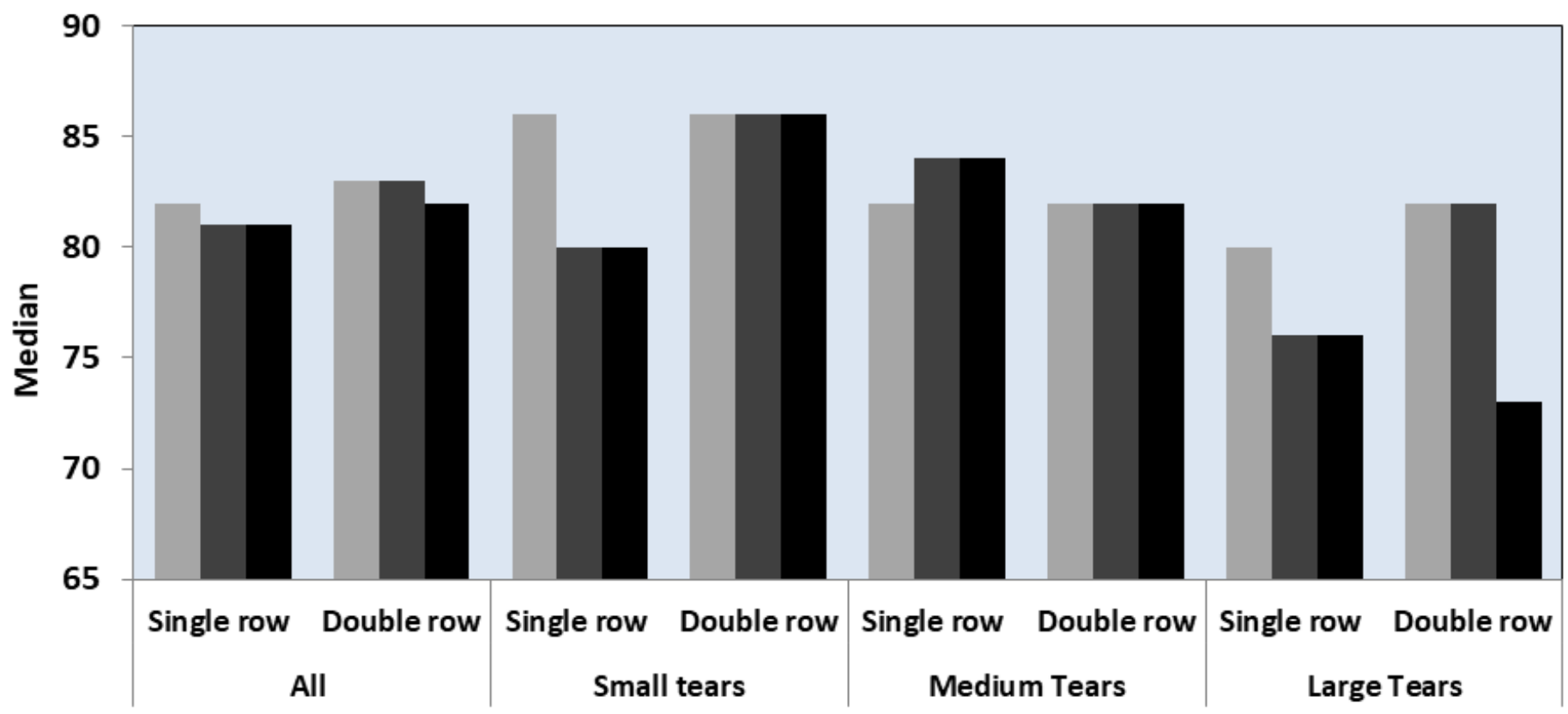

Group A $\quad$ Group B $\quad$ Group C

Figure 2 


\section{UCLA Score}

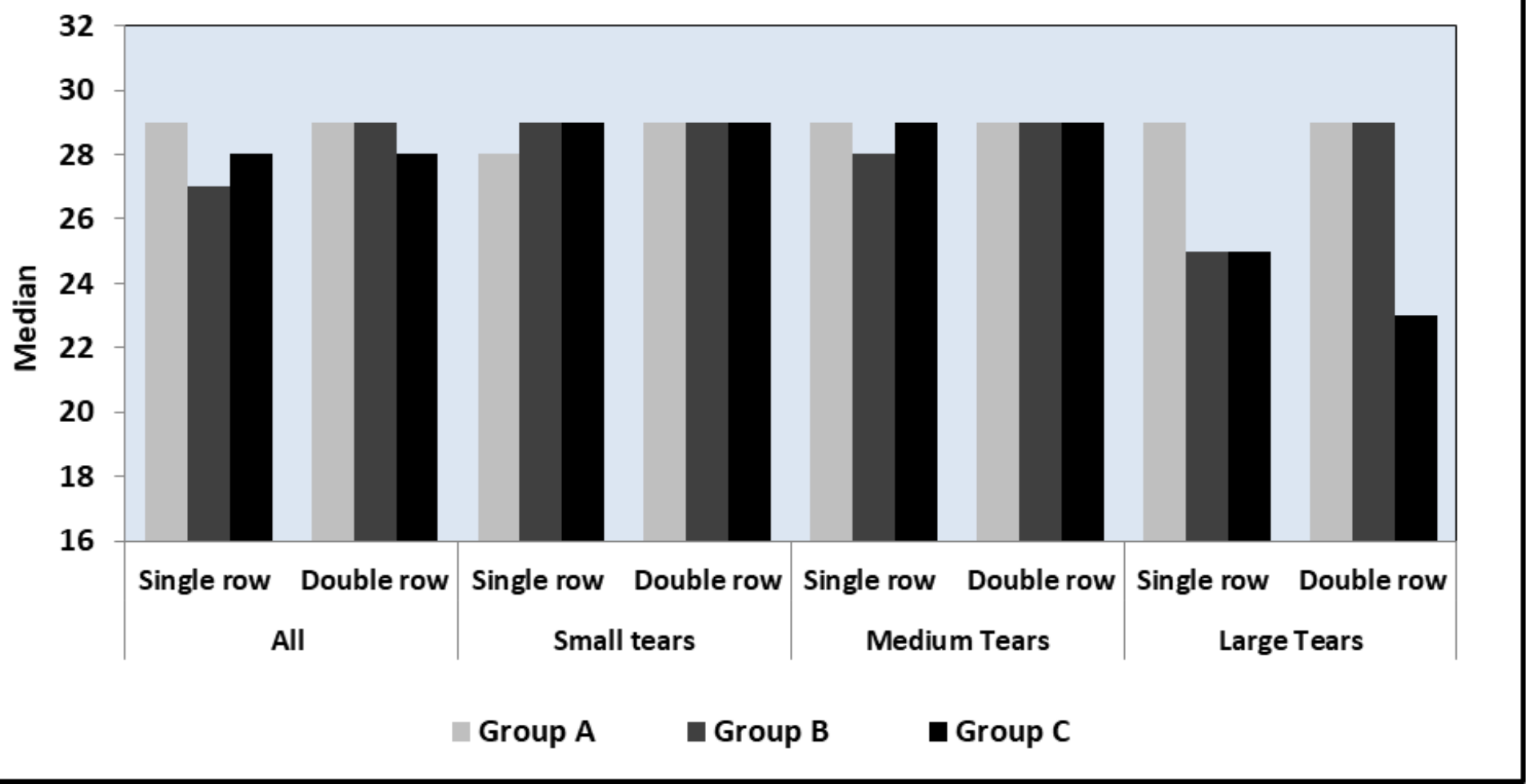

Figure 3

Distribution of the UCLA scores. 